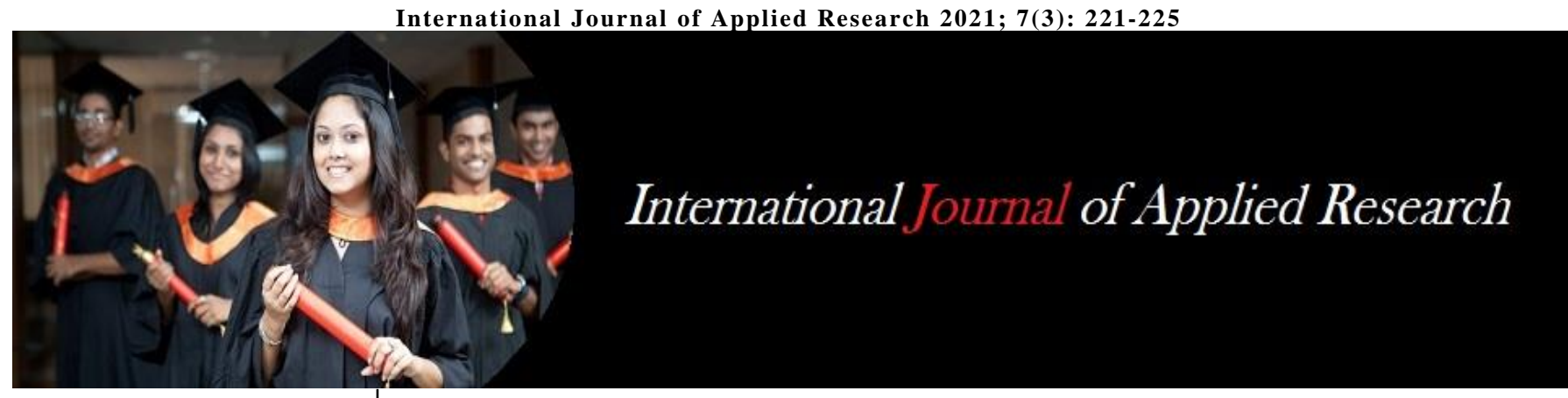

ISSN Print: 2394-7500

ISSN Online: 2394-5869

Impact Factor: 8.4

IJAR 2021; 7(3): 221-225

www.allresearchjournal.com

Received: 22-01-2021

Accepted: 24-02-2021

Akshay Joshi

S. S. V. P. S Bapusaheb

Shivajirao Deore College of

Engineering, Dhule,

Maharashtra, India

Dr. ER Deore

S. S. V. P. S Bapusaheb

Shivajirao Deore College of

Engineering, Dhule,

Maharashtra, India
Corresponding Author:

Akshay Joshi

S. S. V. P. S Bapusaheb

Shivajirao Deore College of

Engineering, Dhule,

Maharashtra, India

\section{Performance characteristics of heat loss of the inverted hemispherical solar concentrator receiver}

\author{
Akshay Joshi and Dr. ER Deore
}

DOI: $\underline{\text { https://doi.org/10.22271/allresearch.2021.v7.i3d.8400 }}$

\section{Abstract}

Convection losses are essential factors in determining thermal power systems performance by using solar concentrators. To achieve optimum thermal performance, the design of the cavity receivers plays a significant role. These cavity receivers come in different shapes like parabolic, spherical, cylindrical, etc., and can be used with solar dish concentrators for process heat applications. In this experimental study, the natural convection loss occurring from a hemispherical cavity receiver is investigated at medium temperature levels, based on the corresponding change in that receiver's inclination. It is found that the heat loss was minimum for $90^{\circ}$ and maximum for $0^{0}$.

Keywords: total heat loss, natural convection, conduction and radiation, solar dish, cavity receiver, hemispherical cavity

\section{Introduction}

The use of concentrating solar thermal systems has great potential for generating power. The parabolic dish-receiver system is currently one of the exemplary systems available. This system typically consists of a reflector in the form of the parabolic dish with a downwardfacing receiver at the dish's focus. Although its' more excellent applications, these systems are prone to changing environmental conditions such as wind, solar isolation, and ambient temperature. When these ecological variations are entwined with varying receiver angles, it affects the overall receiver performance, leading to energy loss. These total energy losses of solar receivers include conduction through the receiver's insulation, convection, and radiation from the aperture opening to the ambient environment. Here the conduction heat loss is dependent on the receiver wall temperature and the material of the insulation used. In contrast, the radiation heat loss is dependent on the temperature, emissivity/absorptivity, and the shape factors of the receiver walls, whereas the convective heat losses from these solar cavity receivers are found to be dependent on various parameters like receiver inclination, receiver wall condition, ratio (L/D), opening ratio (d/D) and external wind. As these factors contribute a significant fraction of the energy loss, it is essential to effectively minimize it to improve the system's efficiency.

It is observed from the literature that apart from the other mode of losses, the convective heat transfer contributes a significant share in the thermal losses and while the above attributes are the reason due to which analysis of convective losses from solar cavity receivers are complicated when compared to that of heat transfer due to conduction and radiation. Research of flow and heat transfer for cavity receivers can greatly help estimate the thermal performance and optimize the receivers' design to determine its conduction and radiation analytically. However, this is not the case for natural convection because of the complexity in geometry, temperature, and velocity fields around the receiver, making it challenging to use existing analytical methods to predict the convective heat losses. But the heat characterization of the solar receiver can be accurately determined with the field test. However, a field test requires a complete setup of a concentrator that involves cost and time. The present study is to develop a method and apparatus that can simulate the receiver's field conditions in the laboratory. The corresponding data generated can easily be correlated to the field situation. 
Therefore, many significant investigations are conducted on natural convection heat transfer in open cavities. For instance, Siangsukone and Lovegrove ${ }^{[2]}$ presented work on modeling and simulation of the Australia National University (ANU) $400 \mathrm{~m}^{2}$ paraboloidal dish concentrator system with a direct steam-generating cavity receiver and the steam line. Taumoefolau and Lovegrove ${ }^{[3]}$ presented an experimental investigation based on an isothermal electrically heated model cavity receiver. Kumar and Reddy [4] proposed a two-dimensional model to estimate the approximate natural convection heat loss from the modified cavity receiver of a fuzzy focal solar collector concentrator. Kumar and Reddy ${ }^{[5]}$ performed a comparative study to predict the natural convection heat loss from the cavity, modified cavity, and semi-cavity receivers. Reddy and Kumar ${ }^{[6]}$ also presented a numerical study of combined laminar natural convection and surface radiation heat transfer in a modified cavity receiver of a solar parabolic dish collector. Prakash et al. ${ }^{[7]}$ have reported experimental and numerical studies of the steady state convection heat losses from a downward-facing cylindrical cavity receiver. Nusselt number correlations as a function of receiver aperture diameter were proposed for the natural convection heat losses from all the info points. Le Roux et al. ${ }^{[8]}$ used the second law of thermodynamics to optimally size a modified cavity receiver under steady-state so that the parabolic dish system can have maximum net power.

Minimizing the natural convection has been seen as an efficient method to enhance cavity receivers' thermal efficiency. Some investigations are reported on the reduction in heat loss of the cavity receiver. Kribus et al. [9] designed and demonstrated the multistage receiver's operation under elevated temperatures to realize high working temperature and thermal efficiency.

As per the literature observations, the bulk of cavity receivers with solar systems studied are generally parabolic or cylindrical. During this study, the experimental investigation on natural convection losses in cavity receivers used with solar collector concentrators has been conducted on inverted hemispherical cavity shape. The aim of the study is to develop an experimental setup that was wont to simulate the receiver heat loss within the laboratory and to calculate the warmth loss from an inverted hemispherical receiver in natural convection mode.

\section{Experimental Setup and Methodology}

The solar concentrators use cavity receivers at the parabolic dish's focus, which receives concentrated heat flux from the solar concentrators. The heat flux incident on these receivers is partly absorbed, and rest is lost by way of different modes of thermal losses. The solar radiation is received by keeping at least one face of the solar receivers exposed while the rest system is shielded with proper insulation, due to convective currents of the surrounding this exposed face of the solar receiver losses heat, which is paramount to understand the performance of the solar thermal system for the correct estimation of losses from the receiver. To establish the receiver's performance at different operating conditions, it is required to accurately measure the losses.

\subsection{Experimental setup.}

In this study, a hemispherical receiver is set up for the investigation of the heat loss. The hemispherical receiver is inverted and is provided with a stand, as shown in Fig.1.
The receiver can be positioned to various angles with a fulcrum arrangement supplied with the frame. The receiver used in this study, as shown in Fig.2, is a hemisphere with the copper tube in its' cavity. The copper tube with a diameter of $0.010 \mathrm{~m}$ (ID) has 19 turns along the receiver's circumference with $2-3 \mathrm{~mm}$ of spacing between each turn of that coil. The water tank of 16lit capacity is provided with an electrical heater of $2 \mathrm{kw}$ capacity. The constant head in the tank is maintained with the help of float arrangement. The tank's water is allowed to flow towards the receiver through a valve arrangement that keeps the water's flow rate reaching the receiver. The water temperature is measured with a K-type thermocouple which has its terminals at the inlet and outlet for the temperature measurement during the study.

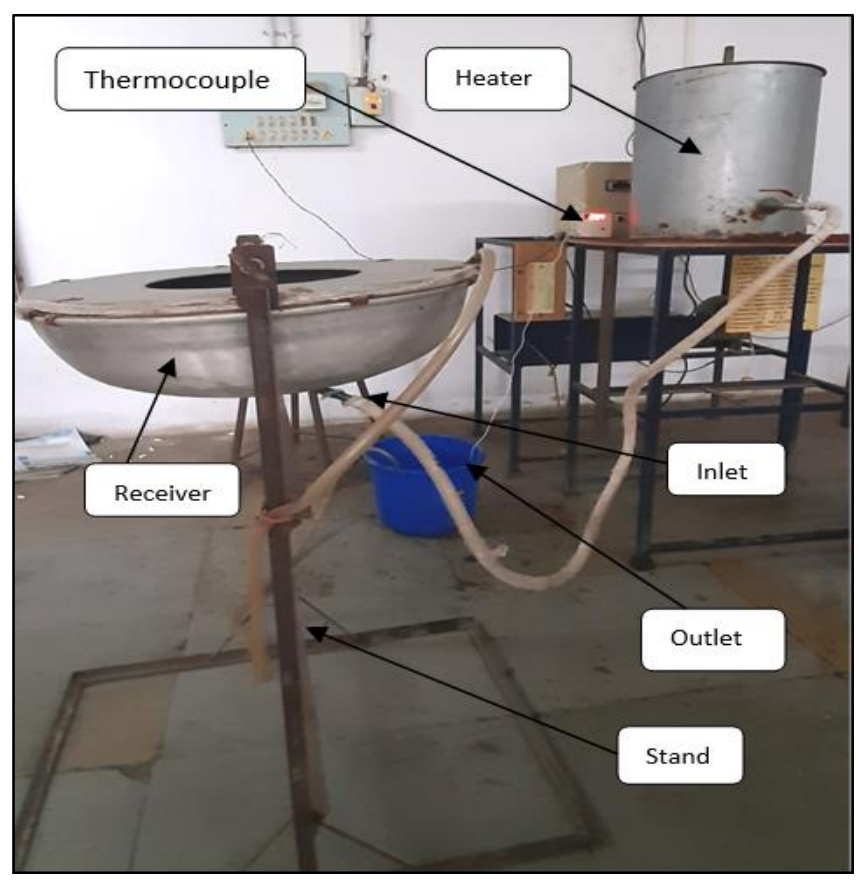

Fig 1: Experimental Setup

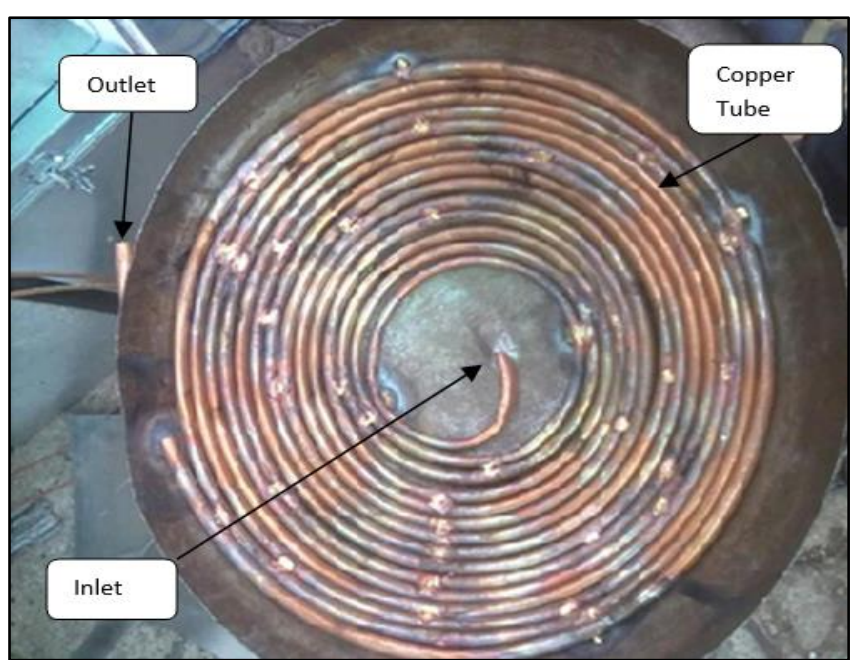

Fig 2: Hemispherical Receiver

\subsection{Experimental Methodology}

The on-flux and off-flux mode of testing is used to determine the heat loss from the concentrator receiver. The on-flux method is when the testing is carried out at the actual conditions, while the off-flux mode is determined experimentally in a laboratory. The experimental setup's 
schematic is shown in Fig.1, an upward-facing hemispherical cavity receiver supported on a stand. The receiver can be inclined to various angles with respect to horizontal in $30^{\circ}$ variations. Having 16 lit of capacity with a heater of $2 \mathrm{~kW}$ total wattage, the hot water from the tank is circulated in the receiver. A liter flask measures the hot water's mass flow rate entering the receiver, which is circulated at constant inlet temperature through the receiver. The temperatures of the working fluid in the tube are measured at four locations (including the outlet) using a Ktype thermocouple. The system is operated under the following conditions, which are as follows:

1. The water exiting from the receiver flows back to the storage tank.

2. The inlet temperature and the velocity of the working fluid are specified.

3. Adiabatic condition is assumed for the cavity insulation.

4. Hemispherical enclosure walls are maintained at the ambient temperature of $27^{\circ} \mathrm{C}$.

The working fluid used for the heat loss measurement was hot water, and the experiment was carried out with different inlet temperatures varying from $50{ }^{\circ} \mathrm{C}$ to $75{ }^{\circ} \mathrm{C}$. The hot water is supplied from the bottom of the receiver and leaves the receiver from the outlet provide at the top, which ensures the high temperature at the bottom and low near the aperture. The flow rate of water is kept constant at $0.013 \mathrm{~kg} / \mathrm{s}$. For steady-state operation, the experiment is continually carried out till the outlet temperature remains steady for about half an hour, which takes the time about $2 \mathrm{hr}$ and then the heat is measured.

\section{Test Results and Discussions}

The temperature drop of the working fluid within the coil is taken as the heat loss occurring from the receiver at any angle $\beta$ is calculated as,

$\mathrm{Q}_{\text {total }}=m \mathrm{C}_{\mathrm{p}}\left(\mathrm{T}_{\mathrm{i}}-\mathrm{T}_{\mathrm{o}}\right)$

Where $m$ is the mass flow rate of fluid, $\mathrm{C}_{\mathrm{p}}$ is the specific heat of the working fluid, $\mathrm{T}_{\mathrm{i}}$ is the fluid inlet temperature, $\mathrm{T}_{\mathrm{o}}$ is the fluid outlet temperature, and $\mathrm{T}_{\mathrm{a}}$ is the ambient temperature.

Fig. 3 represents the Total Heat Loss $\mathrm{Q}_{\text {total }}$ plotted against the temperature difference $\left(T_{m}-T_{o}\right)$, where $T_{m}$ is the mean temperature of $T_{i}$ and $T_{0}$. The mean fluid temperature is taken as the mean receiver temperature. An increase in this temperature leads to higher convection currents of air within the cavity-causing higher convective losses.

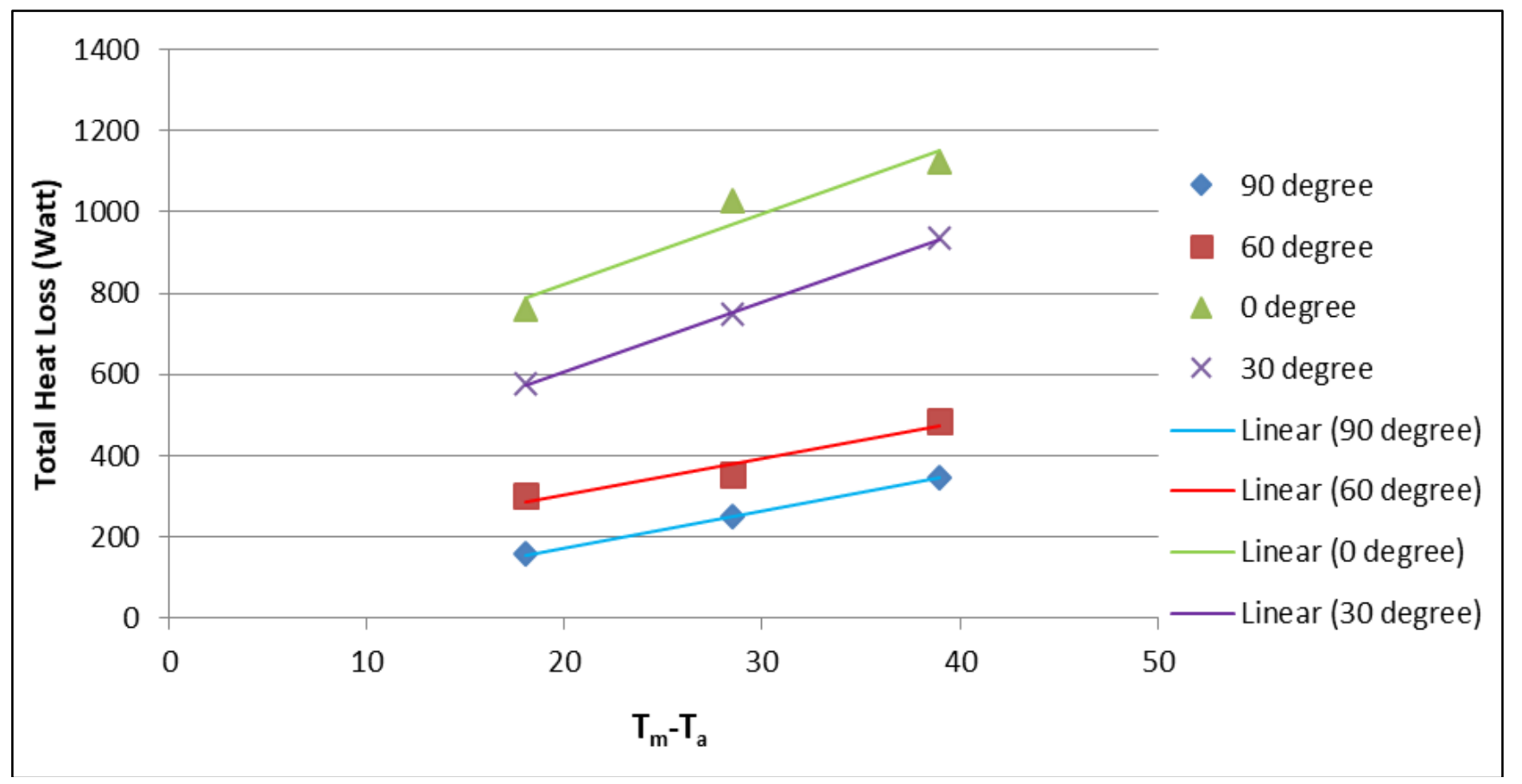

Fig 3: Total Heat Loss Vs $\left(T_{m}-T_{a}\right)$ graph

The decrease in the convective loss with the increase in the receiver inclination is due to the formation of the stagnation zone of air within the cavity as the cavity is tilted from $0^{0}$ to $90^{\circ}$. Therefore higher the stagnation zone area, the lower are the convective losses that vary with the cavity's inclination. The total heat loss increases as the temperature difference increases. In contrast, the loss decreases with an increase in receiver angle represented in Fig.4, showing the total heat loss $\mathrm{Q}_{\text {total }}$ plotted against the angle of receiver $\beta$. Here from the plotted graph, the heat loss is maximum for $0^{0}$ inclinations and minimum for $90^{\circ}$ inclinations. 


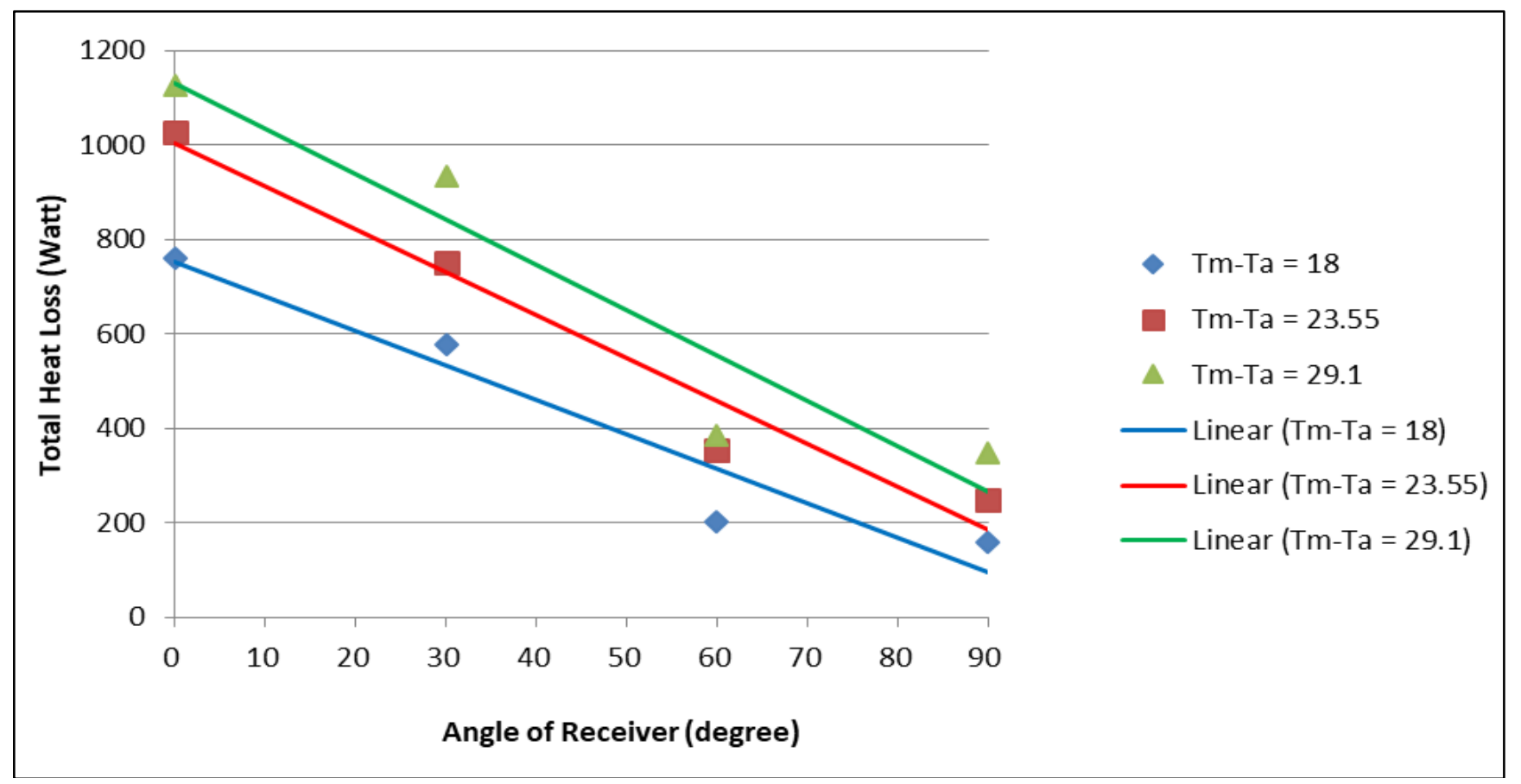

Fig 4: Total Heat Loss Vs Angle of Receiver graph

\subsection{Natural Convection Heat Loss}

Natural convection loss at different angles is calculated by subtracting conduction and radiation losses at corresponding angles from the total heat loss $\mathrm{Q}_{\text {total, }}$ which is given as

$\mathrm{Q}_{\text {convection }}=\mathrm{Q}_{\text {total }}-\mathrm{Q}_{\text {conduction }}-\mathrm{Q}_{\text {radiation }}$

Where $\mathrm{Q}_{\text {conduction }}$ is the conduction loss, and $\mathrm{Q}_{\text {radiation }}$ is the radiation loss which is calculated theoretically from the equations

$\mathrm{Q}_{\text {radiation }}=\sigma . \varepsilon$. A. F. $\left(\mathrm{T}_{\mathrm{m}}^{4}-\mathrm{T}_{\mathrm{m}}^{4}\right)$

$\mathrm{Q}_{\text {conduction }}=\mathrm{k} \cdot \mathrm{A} \cdot\left(\mathrm{T}_{\mathrm{m}}-\mathrm{T}_{\mathrm{a}}\right) / \mathrm{x}$
For calculation of conductive losses, the receiver's aperture is closed by a wooden block insulated with glass wool. Whenever the hot water is circulated in the temperature range of $500 \mathrm{C}$ to $750 \mathrm{C}$, the conduction and radiation losses are obtained for all fluid inlet conditions corresponding to four different angles of the receiver. After theoretically calculating the conduction and radiation losses from equations (3) and (4), the convection losses for any corresponding inclinations are calculated by using equation (2). Convection heat loss for a cavity at four tilts has been calculated using the above equations, and the corresponding graphs are plotted. Fig.5 shows the variation of convection heat loss with temperature difference (Tm - Ta), while Fig.6 represents the convection loss dependency on the receiver angle.

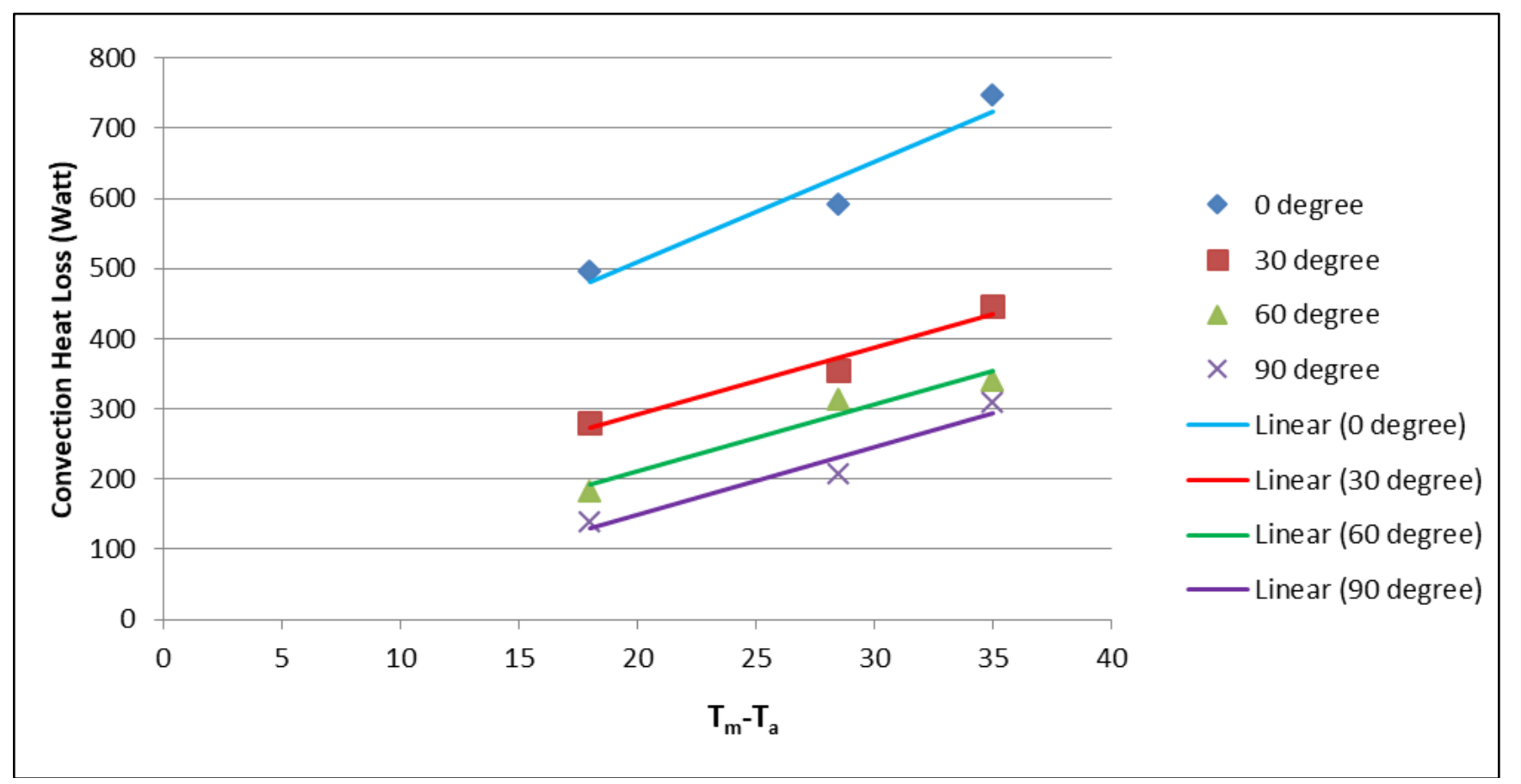

Fig 5: Convection Heat Loss Vs $\left(\mathrm{T}_{\mathrm{m}}-\mathrm{T}_{\mathrm{a}}\right)$ graph 


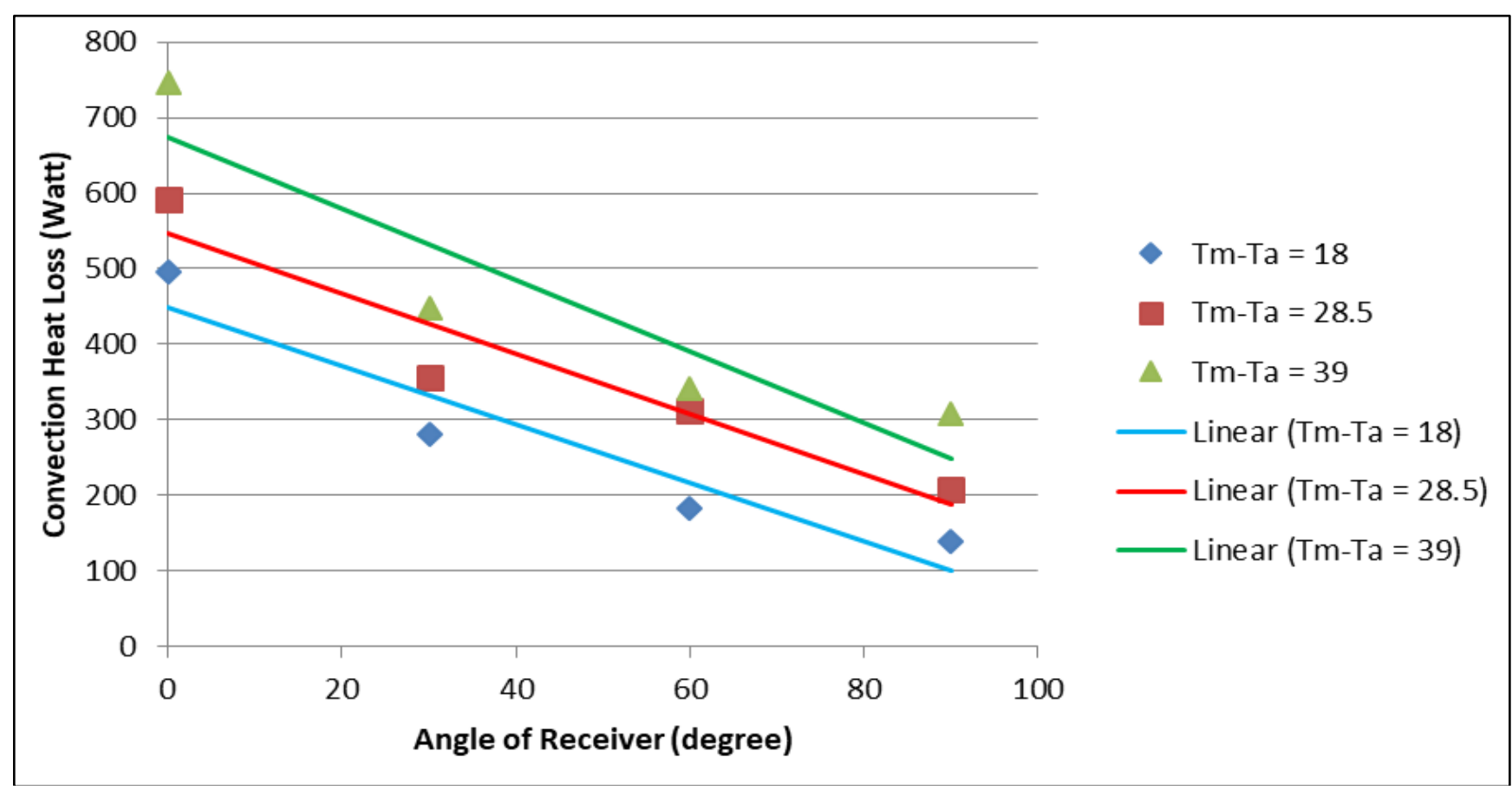

Fig 6: Convection Heat Loss Vs Angle of Receiver graph

The above results show that the convection heat loss increases with the increased temperature difference. Simultaneously, it is also evident that the convective losses decrease with an increase in the cavity's inclination, which follows a similar trend as that of the total heat loss. At $90^{\circ}$ inclinations, as most of the receiver is in the stagnation zone, whereas the convection heat loss occurs only at the aperture surface, the convection heat loss is minimal. As the receiver's angle decreases, the convective zone becomes significant due to which the heat loss increases. At $0^{0}$ inclinations, natural convection heat loss is dominant, while at $90^{\circ}$ inclinations, conduction and radiation heat losses are dominant.

\section{Conclusions}

In this study, we determined the experimental heat loss from the inverted hemispherical receiver was determined. The aim of the project was to identify the total heat loss and convection heat loss from the receiver. We observed that the heat loss is minimum at $90^{\circ}$ inclination while the maximum for $0^{0}$ inclination. However, further analysis is required to compare the use of the inverted hemispherical receiver to that of the hemispherical receiver facing downward to establish the comparison of the receivers.

\section{References}

1. Patil M, Jahagirdar R, Deore E. Experimental Investigation of the Heat Loss from Hemispherical Solar Concentrator Receiver, Frontiers in Heat and Mass Transfer 2012;3(3).

2. Siangsukone P, Lovegrove K. Modeling of a steam based paraboloidal dish concentrator using the computer source code TRNSYS, Proceedings of Solar Australian and New Zealand Solar Energy Society 2002, 1.

3. Taumoefola T, Lovegrove K. An Experimental Study of Natural Convection Heat Loss from a Solar Concentrator Cavity Receiver at Varying Orientation, Proceedings of Solar- Australian and New Zealand Solar Energy Society 2002, 1.
4. Sendhil Kumar N, Reddy KS. Numerical investigation of natural convection heat loss in modified cavity receiver for fuzzy focal solar dish concentrator, J Sol. Energy 2007;81:846-855.

5. Sendhil Kumar N, Reddy KS. Comparison of receivers for solar dish collector system, Energy Convers. And Management 2008;49:812-819.

6. Reddy KS, Sendhil Kumar N. Combined laminar natural convection and surface radiation heat transfer in a modified cavity receiver of solar parabolic dish, J Therm. Sciences 2008;47:1647-1657.

7. Prakash M, Kedare SB, Nayak JK. Investigations on heat losses from a solar cavity receiver, J Sol. Energy 2009;83:157-170.

8. Le Roux WG, Bello-Ochende T, Meyer JP. Thermodynamics optimization of an integrated design of a small-scale solar thermal Brayton cycle, Int. J Energy Research 2012;36:1088-1104.

9. Kribus A, Doron P, Rubin R, Karni J, Reuven R, Duchan S et al. A Multistage Solar Receiver: The Route To High Temperature, Sol. Energy 1993;67:3-11.

10. Reddy KS, Sendhil Kumar N. Convection and surface radiation heat losses from modified cavity receiver of solar parabolic dish collector with two-stage concentration, J Heat and Mass Transfer 2009;45:363373.

11. Ngo LC, Bello-Ochende T, Meyer JP. Numerical modeling and optimization of natural convection heat loss suppression in a solar cavity receiver with the plate fins, Renewable Energy 2015;74:95-105. 